\title{
Simulation Analysis of Opportunity Recognition Path of Small and Medium-Sized Manufacturing Enterprises in Dongguan - Comparison between E-commerce and Traditional Relationship Network
}

\author{
Fu Jiang ${ }^{1}$, Fei Lei*1 ${ }^{1}$ Ling Zhang $^{2}$ \\ ${ }^{1}$ School of Management Xinhua College of Sun Yat-sen University Guangzhou, China \\ ${ }^{2}$ School of Management Macau University of Science and Technology Macau, China
}

\begin{abstract}
Small and medium-sized manufacturing enterprises in Dongguan use e-commerce and traditional relationship networks to build paths for market opportunity recognition. Taking the company's monthly average total sales and total capacity as variables, this article employs particle swarm optimization (PSO) to simulate the paths of opportunity recognition in three different modes, namely the single e-commerce mode, the single traditional relationship network and their hybrid mode. The results reveal that: for the single ecommerce mode, the capacity utilization rate is very low; for the single traditional relationship network, changes in learning factor will not affect the choices of the enterprises; for the hybrid mode, the optimal solution of the three models is reached. But there is a substitution between the enterprise's own learning factor and the group learning factor, which leads to deviation from the optimal solution
\end{abstract}

\section{INTRODUCTION}

Dongguan is a manufacturing and processing industrial center in China. According to the data from Dongguan bureau of statistics, as of the end of 2019, there were more than 1.2 million registered industrial and commercial enterprises, of which 10,069 were largescale enterprises. Small and medium-sized enterprises reached more than 1.1 million, of which manufacturing enterprises account for $40 \%$, that is, more than 500,000 . What kinds of opportunity recognition path do these small and medium-sized manufacturing enterprises adopt in the market? What are the significant differences between different opportunity recognition paths? Researches on these problems have a strong practical and theoretical significance. There are plenty of small and medium-sized manufacturing enterprises in Dongguan. Also, there are many paths and they intersect each other, which constitutes a complex system. Therefore, this paper compares two representative paths of opportunity recognition, including e-commerce and traditional interpersonal network, and conducts simulation analysis through PSO, in order to find out the key differences between the two paths and explore the important factors for the effective selection of small and medium-sized manufacturing enterprises under the two paths.

\section{LITERATURE REVIEW}

\section{A. OPPORTUNITY RECOGNITION}

In [1] opportunity recognition is regarded as a key issue in entrepreneurship theory, and the research should be on opportunity itself, not on the subject of opportunity recognition. There are two different representative views about the definition of opportunity. One idea is to distinguish entrepreneurial opportunities and profit opportunities. This idea emphasize that entrepreneurial opportunities are situations in which new products, new services, new materials, new markets, and new organizational methods can be introduced through new means, or purpose-means relationships[2]. Another view is that entrepreneurial opportunity includes profit opportunity. For example, [3] believes an entrepreneurial opportunity is a viable, profit-seeking, potential business, or offering an innovative new product or service to the market, or improving an existing product or service, or mimicking a profitable product or service in an unsaturated market. We argue that it is not necessary to identify the differences between those two. The reasons is presented as follows. Firstly, regardless of emphasizing innovation or embodying conventional behavior, both of them are the basis of enterprise production and development. Secondly, both of them show the performance results through profit. Finally, the two are actually mixed in the enterprise behavior so that 
no enterprise only depends on innovative opportunities to survive without conventional business. Meanwhile, any innovative opportunities are derived from the expansion of conventional business. The connotation of opportunity in this paper includes three key characteristics: gestating economic profit, representing the existence of market demand, and relying on the active development and utilization of enterprises.

Therefore, Opportunity recognition is a commercial cognitive process that produces business ideas, business concepts, business intentions [4], and focuses on the evaluation of opportunities [5]. Furthermore, the relationship among opportunity recognition, opportunity evaluation and opportunity development is iterative and recursive [6]. Finally, opportunity recognition reflects the initiative of the subject to respond to the market. Therefore, we believe that opportunity recognition is the first step in the process of cognition of market demand. Through the combination of means and purpose, subjectivity and objectiveness, and through interaction between the subject and market information, it ultimately helps the subject obtain economic profits.

\section{B. OPPORTUNITY RECOGNITION PATH}

Opportunity recognition path is a comprehensive and procedural concept that covers the three processes, including opportunity recognition, opportunity evaluation and opportunity development. It is not only the market information acquisition and evaluation path, but the effectiveness of the path can be evaluated by the economic profit after the opportunity development. Opportunity recognition path means that when the entities face with many external market information points, through the acquisition, search, evaluation, development, they establish a stable relationship to obtain economic profits in this path. Enterprises face multiple market opportunities that are randomly distributed. These opportunities can be divided into two main types: market arbitrage opportunities (imbalance between supply and demand of products and services) and technical arbitrage opportunities (innovation or imitation of innovation) [7]. Secondly, enterprises conduct external search through different means to obtain market opportunity information. Thirdly, they evaluate and compare the market opportunity information after searching, and determines the optimal opportunity recognition path at last.

\section{MEANS OF OPPORTUNITY RECOGNITION PATH}

Enterprises have diversified means of opportunity recognition path. However, this paper focuses on small and medium-sized manufacturing enterprises in Dongguan, which mainly rely on two ways of opportunity recognition path: e-commerce and traditional relationship network. Since 2000, a large number of e-commerce platforms have emerged in China to meet the needs of various market entities due to geographical segmentation, and it has become the mainstream for enterprises to obtain market opportunities through e-commerce platforms. The representative ecommerce platforms include TaoBao, Tmall, Amazon, Jingdong, Suning e-shopping, Vipshop and so on. Traditional relationship networks include multiple channels such as family, friends, colleagues, mentors, professional forums and chambers of commerce. Research shows that information obtained from colleagues, mentors, professional forums and chambers of commerce has positive influences on opportunity recognition and there are differences among the three influences, while information obtained from family and friends has no direct influence on opportunity recognition [8].

\section{Model ANd Data Acquisition}

\section{A. MODEL INTRODUCTION}

PSO was proposed by Kennedy and Eberhart in 1995 [9]. It is one of the modern algorithms for intelligent optimization of social behaviors base. In this paper, small and medium-sized manufacturing enterprises in Dongguan are abstracted as particles without mass and volume. Enterprise $i$ is abstracted as particle $i$, which is expressed as vector $X_{i}=\left(X_{1}, X_{2}, \ldots, X_{n}\right)$, and the speed of search opportunities is expressed as the vector $V_{i}=\left(V_{1}\right.$, $\left.V_{2}, \ldots, V_{n}\right)$. Each particle determines the matching value through the objective function, that is, the matching degree of enterprise resources and market opportunities. As the enterprise has a full understanding of its own resource information, it can know the best position (the variable pbest) discovered so far, that is, the market opportunity position with the best matching with itself. Besides, the enterprise also knows its current market opportunity position $X_{\mathrm{i}}$, which is generated by the experience of the enterprise's historical operation. The enterprise also knows the best market opportunity location (the variable gbest) discovered by the entire group by far, and gbest is the best of all pbest values, reflecting the shared experience of the peers in the enterprise group. Then the enterprise will decide what to do next based on its own best experience and that of its peers. The enterprise will update its next action by tracking the two extreme values pbest and gbest through multiple actions, which is regarded as an iterative process. After finding the two optimal values, the enterprise updates its speed and position through formula (1).

$V_{i}=\omega V_{i}+C_{1} \times \operatorname{rand}(\quad) \times\left(\right.$ pbest $\left._{i}-X_{i}\right)+C_{2} \times \operatorname{rand}(\quad) \times\left(\right.$ gbest $\left._{i}-X_{i}\right)$

- $i=1,2,3 \ldots, M . M$ is the total number of enterprise particles in the population; $V_{i}$ is speed that enterprise searches market opportunities; $X_{i}$ is the current position of the enterprise.

- Rand ( ) is the random number of the interval $(0$, 1).

- $\quad C_{1}$ and $C_{2}$ are learning factors. $C_{1}=0$ means that enterprise have no experience of their own, and $C_{2}=0$ means that enterprise particles have no experience of group sharing. When the learning factor is 0 , enterprise particles will search blindly, and it is difficult to find the optimal solution.

- $\omega$ is the correction weight factor of the search speed. 


$$
\omega(t)=\left(\omega_{\text {ini- }}-\omega_{\text {end }}\right)\left(G_{k}-g\right) / G_{k}+\omega_{\text {end }}
$$

$G_{k}$ is the maximum evolution algebra. $\omega_{\text {ini }}$ is the initial inertia weight. $\omega_{\text {end }}$ is the inertia weight when iterating to the maximum algebra. The typical values of $\omega_{\text {ini }}$ and $\omega_{\text {end }}$ is 0.9 and 0.4 , respectively.

\section{B. DATA ACQUISITION}

In this paper, data of water purification equipment manufacturing industry in Dongguan is selected as the basis for simulation analysis. Small and medium-sized manufacturers of water purification equipment in Dongguan seek orders on different e-commerce platforms. Meanwhile, they also obtain orders through traditional relationship networks. The first type of order is characterized by small quantity, high order frequency and high profit margin. The second type of order is characterized by large quantity, low order acquisition frequency, low profit per item and large overall profit in absolute amount. Besides, this type contains many acquaintance relationships or core customer relationships. Generally, orders obtained from ecommerce platforms are those which are fewer types in batches such as home and office, while orders obtained from traditional relationship networks are those which are larger types in batches such as engineering and foreign trade. Details can be seen in TABLE I and TABLE II. TABLE I shows the monthly average data and sales profit of orders obtained by small and medium-sized water purifiers in Dongguan on 12 e-commerce platforms in 2019. These e-commerce platforms include Taobao, Tmall, Amazon, JD, Suning e-shopping and other platforms. For example, the sales volume from the first platform is 95 pieces and the corresponding gross profit is 2, 375 hundred Chinese Yuan (CNY). TABLE II depicts the monthly average data of orders from traditional relationship networks, including family, friends, classmates, fellow villagers and industry chain stakeholders.

TABLE I. ORDER FROM ECOMMERCE PLATFORM

\begin{tabular}{lll}
\hline NO. & $\begin{array}{l}\text { Sales volume } \\
\text { (pieces) }\end{array}$ & $\begin{array}{l}\text { Gross profit from sales } \\
\text { (Hundred CNY) }\end{array}$ \\
\hline 1 & 95 & 2,375 \\
2 & 4 & 80 \\
4 & 32 & 800 \\
5 & 23 & 552 \\
6 & 72 & 1,944 \\
7 & 80 & 2,240 \\
8 & 62 & 1,302 \\
9 & 65 & 1,625 \\
10 & 46 & 1,242 \\
11 & 12 & 420 \\
12 & 28 & 588 \\
\hline
\end{tabular}

TABLE II. ORDER FROM TRADITIONAL RELATIONAL NETWORKS

\begin{tabular}{lll}
\hline No. & $\begin{array}{l}\text { Sales volume } \\
\text { (pieces) }\end{array}$ & $\begin{array}{l}\text { Gross profit from sales } \\
\text { (Hundred CNY) }\end{array}$ \\
\hline 1 & 630 & 6,930 \\
2 & 990 & 10,680 \\
3 & 1,062 & 15,620
\end{tabular}

$4 \quad 770 \quad 10,010$

\section{SIMULATION AND RESULT ANALYSIS}

\section{A. MODEL PARAMETER SETTING}

- The total number of enterprises in the group is set to 30 , so $M=30$.

- Maximum number of iterations of enterprise particles (MaxIt) is set to 30 .

- According to the typical setting, the inertia factor of enterprise particles is 0.8 . The initial position and initial velocity of enterprise particles are generated randomly according to the expansion matrix of order volume and sales profit.

- The learning factors $C_{1}$ and $C_{2}$ will be set in the following different models, and the results will be compared in multiple sets.

- According to the statistical analysis of enterprise data, the maximum monthly average production capacity of the enterprise is 1269 pieces.

- The objective function employs Eq. (1) above.

With the employment of MATLAB software, the simulations are carried out under three different mode, including single e-commerce mode, traditional relationship networks and their combination. The results will be given in the following part.

\section{B. RESULTS OF SIMULATION}

The results of simulation in the mode of single ecommerce platform are revealed in TABLE III. Obviously, the maximum s gross profit from sale is 14 , 236 and the corresponding total utilized capacity is 556 pieces when learning factor $C_{1}$ and $C_{2}$ are 1.8 and 1.8 , respectively. TABLE IV shows the results that the enterprise obtains orders from the traditional relationship networks. No matter what the values of learning factors are, the optimal solution is constant. Compared with the first mode, the capacity utilization is significantly enhanced and the sales profit is also improved. The results of simulation in the hybrid mode are depicted in TABLE $\mathrm{V}$. It is quite clear that the maximum $\mathrm{s}$ gross profit from sale is 20,458 and the corresponding total utilized capacity is 1,263 pieces when learning factor $C 1$ and $C 2$ are 1.8 and 1.2 , respectively.

TABLE III. SIMULATION RESULTS UNDER E-COMMERCE PATH

\begin{tabular}{lll}
\hline $\begin{array}{l}\text { Learning } \\
\text { factors }\end{array}$ & $\begin{array}{l}\text { Gross profit from sale } \\
\text { (Hundred CNY) }\end{array}$ & $\begin{array}{c}\text { Total utilized capacity } \\
\text { (pieces) }\end{array}$ \\
\hline$C 1=1.5$ & 13,066 & 505 \\
$C 2=1.5$ & 13,488 & 531 \\
$C 1=1.7$ & $\mathbf{1 4 , 2 3 6}$ & $\mathbf{5 5 6}$ \\
$C 2=1.7$ & 11,294 & \\
$\boldsymbol{C 1}=\mathbf{1 . 8}$ & & 440 \\
$\boldsymbol{C 2}=1.8$ & & \\
$C 1=1.9$ & & \\
$C 2=1.9$ & 11,748 & 467 \\
$C 1=2.0$ & & \\
$C 2=2.0$ & & \\
&
\end{tabular}

TABLE IV. SIMULATION RESULTS UNDER TRADITIONAL RELATIONSHIP NETWORKS 


\begin{tabular}{lll}
\hline $\begin{array}{l}\text { Learning } \\
\text { factors }\end{array}$ & $\begin{array}{l}\text { Gross profit from sale } \\
\text { (Hundred CNY) }\end{array}$ & $\begin{array}{l}\text { Total utilized } \\
\text { capacity } \\
\text { (pieces) }\end{array}$ \\
\hline $\begin{array}{l}\text { No matter what the } \\
\text { values of learning } \\
\text { factors are, the } \\
\begin{array}{l}\text { optimal solution is } \\
\text { constant }\end{array}\end{array}$ & 15,620 & 1,062 \\
\hline
\end{tabular}

TABLE V. SIMULATION RESULTS IN THE HYBRID MODE

\begin{tabular}{lll}
\hline $\begin{array}{l}\text { Learning } \\
\text { factors }\end{array}$ & $\begin{array}{l}\text { Gross profit from sale } \\
\text { (Hundred CNY) }\end{array}$ & $\begin{array}{c}\text { Total utilized capacity } \\
\text { (pieces) }\end{array}$ \\
\hline$C 1=1.8$ & 18,477 & 1,194 \\
$C 2=0.5$ & 18,710 & 1,089 \\
$C 1=1.8$ & $\mathbf{2 0 , 4 5 8}$ & \\
$C 2=1.0$ & 16,291 & $\mathbf{1 , 2 6 3}$ \\
$\boldsymbol{C} \mathbf{1}=\mathbf{1 . 8}$ & & 986 \\
$C 2=1.2$ & $1=1.8$ & \\
$C 2=1.5$ & & \\
\hline
\end{tabular}

\section{Analysis of simulation results}

- In the single e-commerce mode, the enterprise obtains order information through the ecommerce platform. The learning factors $\mathrm{C} 1$ and $\mathrm{C} 2$ are set to be equal. On the one hand, the company's understanding of the information from the e-commerce platform is open and sufficient, and enterprises can learn from each other through the price and the number of orders displayed on the platform. Therefore, the selflearning and shared learning among enterprises are substantially synchronized. On the other hand, when the learning factors take values of $1.5,1.7,1.8,1.9$, and 2.0 respectively, it can be found that the optimal solution can be gained when the value is 1.8 . If the learning factors increase or decrease, the total sales profit and total utilization capacity are lower than the optimal solution. Furthermore, we compared the optimal solution with the maximum capacity, that is 1,269 pieces, and it is found that relying solely on e-commerce to search information will cause most of the company's capacity to be idle.

- In the second mode, the enterprise obtains the order information through the traditional relationship information path. No matter what the values of learning factors are, the optimal solution is constant. Compared with the first mode, it significantly enhance the capacity utilization, and the gross profit from sale is promoted from 1, 269 to 15,620 . This is related to the nature of the project type order in this mode. In the case of large batches, even if the profit rate of a single product decreases, the total sales profit can be guaranteed to increase.

- In the hybrid mode, according to the optimal premise of self-learning factor $C 1=1.8$ in the first mode, the group learning factor $C 2$ was tested at $0.5,1,1.2$, and 1.5 , and it was found that when $\mathrm{C} 1$ was 1.8 and $\mathrm{C} 2$ was 1.2 , the optimal solution could be got. By comparison, the total sales profit and total utilization capacity are better than the first and the second mode, which is also in line with the mode for companies to obtain order information in practice. On the one hand, the enterprise use ecommerce platforms to obtain small batch orders, and on the other hand, it relies on traditional relationships to obtain large batches of engineering orders to ensure that sales profit is maximized under optimal utilization of production capacity. However, when the value of $C 2$ is greater than 1.2 , we find that its solution cannot reach the optimal. When the two modes are mixed, there is a substitution between selflearning and group learning. If there are capacity constraints, enterprises must choose between multiple batches of small batches and small batches of large batches. Moreover, considering the individuality and non-publicity of traditional relationships, the value of group learning cannot reach the level of information sharing on ecommerce platforms.

\section{ConClusions AND MANAGEMENT IMPLEMENTATIONS}

In this paper, PSO is used to simulate the opportunity recognition path of small and medium-sized manufacturing enterprises. We can draw the following conclusions and find the problems hidden in the two modes of searching for market opportunities.

- A variety of market opportunities search paths is used by small and medium-sized manufacturing enterprises, of which e-commerce path has been widely used. According to statistics from ecommerce platforms in the first half of 2019, nearly 20 trillion yuan of transactions were conducted, and the Chinese mainland had about 400 million Internet users. However, through the model test, the single e-commerce path will lead to insufficient capacity utilization of small and medium-sized manufacturing enterprises, which will not be able to achieve a profitable mode of balanced production capacity and sales.

- Traditional relationship networks are still an important market opportunity search path for small and medium-sized manufacturing enterprises. The high-volume order pattern under this path will enable enterprises to effectively utilize their production capacity. However, relying solely on the traditional relationship network, the frequency of order acquisition is low. This article used monthly average data, which may not show this feature well. Compared with the number of batch in first mode, it can be seen that the number of market opportunities recognition is highly less.

- The combination of e-commerce and traditional relationship networks has become the best choice for opportunity recognition of small and medium-sized manufacturing enterprises. The total profit from sales and total capacity utilization are the best. However, considering the relationship between the self-learning factor and 
the group learning factor, we find that there is a substitution effect, that is, the continuous increase of the group learning factor leads to a decline in the total sales profit and the total capacity utilization. The reason is that the market opportunity recognition information in the traditional relationship network is not public, and the company keeps it confidential as its own competitive advantage resource. Once open, it will form an e-commerce platform-like open information, which will intensify competition among enterprises and lead to the loss of market opportunities, thereby reducing the company's total sales profit and total capacity utilization.

According to the above conclusions, small and medium-sized manufacturing enterprises should adopt the hybrid market opportunity mode. In order to solve the problem of mutual substitution of enterprise's selflearning factor and group learning factor, several management policies can be proposed as follows.

Firstly, the effect of economies of scale should be considered. The limitation of total capacity is the precondition for the mutual substitution of learning factors. Therefore, the first measure is to increase the total capacity. Second, the reason for the substitution of enterprise's self-learning factor and group learning factor is caused by the contradiction between information sharing and non-sharing, that is, the boundary limitation of information sharing. However, this information is only market information. If it can be injected by technology and brand factors, the substitution effect will be reduced. Third, the reason why small and mediumsized manufacturing enterprises are faced with insufficient capacity utilization is that due to product homogeneity competition, there are multiple alternative products. If product differentiation can be strengthened, capacity utilization will be expanded under the same conditions.
If small and medium-sized manufacturing enterprises solve the above existing business problems, then they will evolve into standardized manufacturing enterprises. Then, new characteristics of market opportunity recognition mode will emerge, and new results will emerge in the iterative process of mutual inspiration between enterprise's self-learning and group learning.

Corresponding author. This study is partly sponsored by the project "Establishment and Practice of Cloudbased ERP Simulation Teaching Innovation Scheme" (201801024009) of the Ministry of Education.

\section{REFERENCES}

[1] S. Shane and S. Venkataraman, "The promise of entrepreneurship as a field of research,” Acad. Manage. Rev. vol. 25, pp. 217-226, 2000.

[2] J. T. Eckhardt and SA. Shane, "Opportunities and Entrepreneurship,” J. Manag. vol. 29, pp. 333-349, 2003.

[3] R. P. Singh, "A Comment on developing the field of entrepreneurship through the study of opportunity recognition and exploitation," Acad. Manage. Rev. vol. 26, pp. 10-12, 2001.

[4] D. A. Grégoire and D. A. Shepherd, "Technology-market combinations and the identification of entrepreneurial opportunities: An investigation of the opportunity-individual nexus," Acad. Manage. J. vol. 55, pp. 753-785, 2012.

[5] D. A. Grégoire, P. S. Barr, and D. A. Shepherd, "Cognitive processes of opportunity recognition: The role of structural alignment," Organ Sci. vol. 21, pp. 413-431, 2010.

[6] G. T. Lumpkin and B. B. Lichtenstein, "The role of organizational learning in the opportunity-recognition process," Entrep. Theory Pract. Vol. 29, pp. 451-472, 2005.

[7] E. Ozgen and R. A. Baron, "Socail sources of information in opportunity recognition: Effects of mentors, industry networks, and professional forums," J. Bus. Ventur. vol. 22, pp. 174-192, 2007.

[8] S. Anokhin, "Operationalizing opportunities in entrepreneurship research: Use of data envelopment analysis," Small Bus. Econ. Group vol. 37, pp. 39-57, 2011.

[9] J. Kennedy and R. Eberhart, "Particle swarm optimization," Proceedings of ICNN'95 - International Conference on Neural Networks, Perth, WA, Australia, vol. 4, pp. 1942-1948, 1995. 